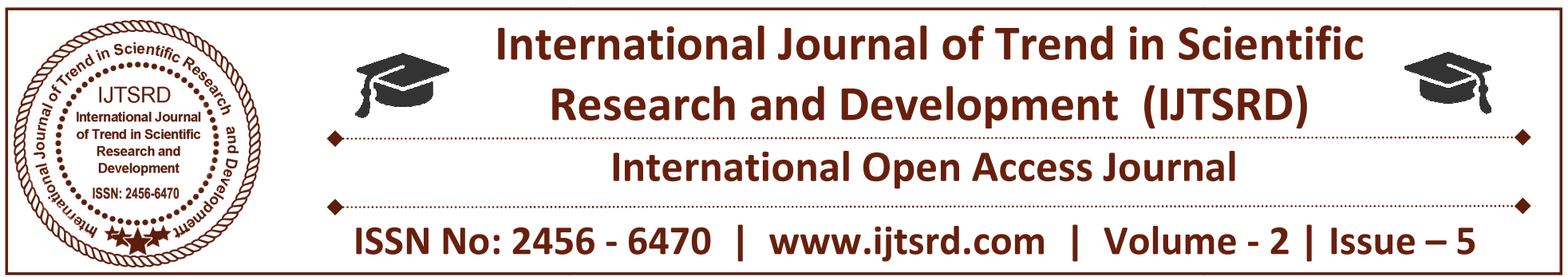

\title{
Analysis of the Characteristics of Municipal Solid Waste in Bauchi Metropolis
}

\author{
Bogoro A. G. \\ Department of Urban and Regional Planning, Abubakar Tafawa Balewa University, \\ Ahmadu Bello Way, Bauchi, Nigeria
}

\begin{abstract}
This paper is mainly aimed at identifying the various streams of solid waste generated in Bauchi metropolis with view to critically analyses their physical characteristics as a basis for recommending appropriate management strategy.
\end{abstract}

Questionnaire, interview guide and observation methods were used to gather information from the sample population of the study area. Major findings revealed that though the area has up to $50 \%$ of the respondent' educated to secondary level but their income level is generally low and the household size is high with teenagers dominating. It is found that over $60 \%$ of solid waste generated in Bauchi metropolis is degradable and can be easily disposed. Though the ratio of polythene, plastics, aluminium and metallic materials in the waste stream is increasing proportionately with growth in income and education level It is recommended that segregation at source should be practiced only in the walled-city in three stages as follows The research recommends that among other things, all households should possess storage facilities. A house-to-house collection method should be introduced in Government Residential Area (GRA), and Bauchi Local Government should resume evacuation of solid waste. Community effort should be integrated in the solid waste evacuation process and more collection centre should be provided

Keywords: Characteristics, Composition, Municipal Solid Waste, Analysis, segregation

\section{INTRODUCTION}

The changing economic trends and rapid urbanization complicate solid waste management (SWM) in Developing countries, consequently, solid waste is not only increasing in quantity but also changing in composition from less organic to more paper, packing waste, plastics, glass, metal wastes among other waste, a fact leading to the low collection rates (Bartone 1993). In order to cope up with these challenges and because of the critical role in protecting the environment and public health, accomplishing effective municipal solid be a priority for emerging cities.

Bogoro , (2007) in his work, the role of women in solid waste management in bauchi metropolis'. He identified the neglect of characterization and composition of the municipal solid waste, as a major factor responsible for poor solid waste management in the area. No deliberate attempt to take into cognizance the characteristics of the solid waste as a factor to determine the appropriate management technique.

Recently even farmers have begun to reject the municipal solid waste, which was highly patronised as organic manure, but now complaining that it contains high proportion of indecomposable materials e.g. leather and plastics and injurious objects e.g. broken bottles, sharp objects

According to Gawaikar(2004), characterization of municipal solid waste helps in determining the quantity of waste generated in a particular location at a particular time of the year. This help in identifying the trend of generation as well as the influencing 
factors. It makes proper planning of solid waste management, determining the size and number of functional units and equipments required for managing the waste, the needed resources for the protection of environment and public health. Characterization is also important to determine its possible environmental impacts on nature as well as on society (Rajesh, et al 2013)).

Treatment methods differ in dealing with different waste streams (Jarusombat, 2002). Options include recycling, land filling, biological treatment (i.e. composting and gasification), and thermal treatment such as mass burn incineration (with or without energy recovery) and fuel burning (Refuse Derived Fuels-RDF)

(Babcock and Wilcox, 2003, Yongzianget al.2003, Glusszynski 1995, Municipal Solid Waste (MSW) data are sometimes measured both in volume (m3/capita/day) and in weight (kg/capita/day).

American solid waste Act (1963) defines solid waste as garbage, refuse and other discarded materials including all materials resulting from all kind of land uses. The United States Environmental Protection Agency described solid waste as any unwanted or discarded material with insufficient liquid content to be free flowing, American Public Works Association (1975). Similarly solid waste is defined as any unwanted and discarded material that is not liquid or gas (Miller, 1994). Olawande (1991) defined solid waste as being a collective name for all the component part of solid waste which may be found in human environment. The definitions given above, attempted to give a clear understanding of what constitutes solid waste in their own view. Generally, solid waste can be defined as those material that results from man's activities and are not in the form of liquid or gas but are compacted and substantial which are thrown away for the fact that they are no longer in use, these materials are both in organic and inorganic form they differ in shapes, sizes, forms and compositions, Mantel (1975). However, the factor of time and place which is influenced by technology reduces the acceptability of absolute definition of solid waste. Generally, uncontrolled dumping, stock piling and inefficiency characterize Municipal Solid Waste (MSW) in cities of developing countries. This often times results into water pollution, air pollution, air and water borne diseases, yet no drastic efforts are directed at necessary improvements.
In many rapidly growing cities solid waste is a major source of concern owing to weak authorities, resource constraint and ineffective sanitary management. Solid waste is supply-driven limited only to local authorities, who are much slower in adjusting to the demands of the residential areas, industries, institutions and even streets and market places despite the various charges levied by the city council.

Solid waste management has a single problem - cost recovery. This is because, traditionally, solid waste services are financed by general revenues from city taxes and levies. Consequently, many municipalities in developing countries spend a large proportion of their budgets on the collection, transport and disposal of solid waste. Their solid waste management is a costly service that consumes between 20 and 50 percent of available operational budgets for municipal services, yet serves no more than 70 percent of the urban inhabitants (Bart one and Bernstein, 1993). Those who do not receive services are the low-income populations concentrated in the peri-urban areas, who either do not prioritize the importance of clean environment or are caught in the abyss of poverty and therefore have more pressing issues. Even those in decent housing areas are living next to mountains of heaps of garbage lying uncollected. The municipal authorities have not made sufficient efforts in educating them apart from asking for service charges.

\section{Materials And Methods}

Bauchi is one of the towns in northern Nigeria within Sudan Savannah vegetation zone. Bauchi Metropolis, the headquarters of Bauchi State, is located between latitudes 9" 00' and 9" 30' North of the Equator and longitudes 10" 25 and 11" 20' East of the Greenwich Meridian as in fig. 1. It occupies a total land area of 3, 604.0 hecteres. It is generally less uniform and grasses are shorter than what is obtainable further South. The topography of Bauchi metropolis is relatively flat in the centre. There are ranges of disjointed hills on the north-eastern part of the metropolis.

The instruments used in data collection includes; structured Questionnaire, oral Interview, direct measurement of solid waste on site, Observation, Photograph and Discussion

Bauchi metropolis has a total population of 318,038 people as at June 2010, population census NPC, (2006). There are 39,675 households in the metropolis which formed the target population of the research. 
The study area was divided into twelve wards (Gunduma) which form the sample frame. From each ward a proportionate unit of household was selected for the purpose of administering questionnaire and interview.

The sample size of this research was determined by the target population size. Since there are 39,675 households in the study area, $4 \%$ of 39,675 households were taken as the sample size which is 1587 households.

For a heterogeneous environment like Bauchi metropolis, where population density, income level and probably occupation which to a great extent determined solid generation and characteristics, are quite varied, systematic random sampling techniques was adopted for the selection of the samples. These techniques are the most appropriate for a social survey because they are scientific and easy to apply.

\section{Results And Discussion}

Projected from 2006 census, the population of Bauchi metropolis stood at 318038 in June 2010, using the National growth rate for urban centres, which is $4.5 \%$. The survey revealed that female dominated with $50.6 \%$ (160 972) of the total population who are traditionally responsible for cooking, sweeping and general cleaning of the environment. Over $50 \%$ of the household heads were found to be employed with the state and local government whose level of payment is relatively low. Teenagers, formed more than $50 \%$ of the entire population, this can be exploited for segregation at household level and organising community labour for evacuation of accumulated solid waste and clear filled drains.

The study found that, out of the 12 wards in Bauchi metropolis, 7 wards are fully enlighten, since up to $36 \%$ of the respondents have secondary education and above because of the high level of enlightenment, they would appreciate the importance of clean environment, it is expected that they will be ready to participate in solid waste management at the household level. However despite the high level of education, the household size is still as high as 8 persons per household and the level of income is relatively low. The findings exhibited a contrary situation where an educationally enlighten society is characterized by low income and high household size. Probably, the situation could be attributed to the type of occupation (mostly civil servants) that dominated in the area.

Bauchi metropolis generates 274 metric tonnes of household solid waste daily with an average of $0.86 \mathrm{~kg}$ per/capita/day, That means those responsible for waste management have a total quantity of 104476 metric tonnes of household solid waste to manage every year. Garbage and ash, which is organic in nature and can be compost, constitute up to $66 \%$ of the household solid waste stream in the metropolis. Income of the household has been found to have the most significant effect on the quantity and composition of the waste generated .Rise income do not only increase the quantity of household waste generated, high income earners also generate more of non- biodegradable solid waste than the low income.

\section{Volume of Solid Waste Generated In Bauchi Metropolitan Area}

Quantitatively, Turaki, (1982) reported that, residential area in Bauchi metropolis; generate an average volume of $0.003 \mathrm{~m}^{3} /$ person/day for high density areas, $0.004 \mathrm{~m}^{3} /$ person/day for medium density areas and $0.005 \mathrm{~m}^{3} /$ person/day for high Density areas. On the other hand, Maikano, (2000) observed that in Bauchi metropolis; high-density residential areas generated an average volume of $0.006 \mathrm{~m}^{3} /$ person/day, medium-density areas generated $0.006 \mathrm{~m}^{3}$ person/day while low-density areas $0.009 \mathrm{~m}^{3} /$ person/day. In the two studies, no account of weight of solid wastes generated was considered and the second researcher, Maikano, claimed that residential density was not a strong factor in determining the quantities of solid wastes generation as asserted by the first researcher.

In another development a World Bank sponsored project, World Bank, (1998) adopted weight as the standard measure for determining amount of solid wastes quantities. For instance data for thirty countries compiled by the World Bank showed that per capita wastes generation ranged between 0.6 and $1.5 \mathrm{~kg} / \mathrm{capita} /$ day for low income countries and 0.8 and $2.0 \mathrm{~kg} / \mathrm{capita} /$ day for industrialized countries. For Nigeria, the average per capita waste generation stood at $1.02 \mathrm{~kg} /$ person/day. The maximum figure was $1.2 \mathrm{~kg} / \mathrm{capita} /$ day recorded in Port Harcourt while the lowest figure was $1.2 \mathrm{~kg} /$ capita/day recorded in Minna. Bauchi metropolis is not one of the high waste generators among Nigerian urban centres. 
International Journal of Trend in Scientific Research and Development (IJTSRD) ISSN: 2456-6470

This study discovered that the average solid waste generation for low income earners was $0.0033 \mathrm{~m}^{3} /$ capita/day, $\quad 0.0040 \mathrm{~m}^{3} /$ capita/day for medium income earners and 0.0046 for high income areas. The overall average stood at $0.004 \mathrm{~m}^{3} /$ capita/day. See table 1 below

\begin{tabular}{|l|l|l|l|l|l|l|l|l|}
\hline \multicolumn{1}{|c|}{ Ward } & \multicolumn{1}{|c|}{ Density } & \multicolumn{1}{|c|}{ Garbage } & Rubbish & Trash & Ash & Polythene & $\begin{array}{c}\text { Total } \\
\left(\mathbf{M}^{\mathbf{3}}\right)\end{array}$ & $\begin{array}{c}\text { Average } \\
\left(\mathbf{M}^{3}\right)\end{array}$ \\
\hline Old G R A & Low & 0.0111 & 0.0057 & 0.0048 & 0.0010 & 0.0053 & 0.0297 & 0.0047 \\
\hline New G R A & Low & 0.0092 & 0.0061 & 0.0052 & 0.0008 & 0.0047 & 0.0260 & 0.0043 \\
\hline F/Mada & Low & 0.0100 & 0.0067 & 0.0060 & 0.0012 & 0.0060 & 0.0299 & 0.0050 \\
\hline Yelwa & Medium & 0.0100 & 0.0060 & 0.0041 & 0.0041 & 0.0040 & 0.0282 & 0.0047 \\
\hline Dan Iya & Medium & 0.0072 & 0.0059 & 0.0052 & 0.0034 & 0.0054 & 0.0271 & 0.0045 \\
\hline Makama & Medium & 0.0052 & 0.0062 & 0.0048 & 0.0037 & 0.0049 & 0.0248 & 0.0041 \\
\hline / Bako & Medium & 0.0070 & 0.0049 & 0.0050 & 0.0024 & 0.0046 & 0.0239 & 0.0040 \\
\hline Nassarawa & High & 0.0039 & 0.0047 & 0.0051 & 0.0043 & 0.0035 & 0.0215 & 0.0036 \\
\hline Dan Kade & High & 0.0033 & 0.0050 & 0.0045 & 0.0051 & 0.0038 & 0.0217 & 0.0036 \\
\hline Dawaki & High & 0.0041 & 0.0032 & 0.0047 & 0.0038 & 0.0028 & 0.0186 & 0.0031 \\
\hline Dan Amar & High & 0.0037 & 0.0028 & 0.0037 & 0.0051 & 0.0026 & 0.0179 & 0.0030 \\
\hline Hardo & High & 0.004 & 0.0037 & 0.0044 & 0.0041 & 0.0038 & 0.0200 & 0.0033 \\
\hline Total $\left.\mathbf{~ M ~}^{\mathbf{3}}\right)$ & & 0.0787 & 0.0609 & 0.0575 & 0.0390 & 0.0514 & 0.2875 & \\
\hline Average $\mathbf{( M}^{\mathbf{3}}$ ) & & 0.0066 & 0.0051 & 0.0048 & 0.0033 & 0.0049 & & \\
\hline
\end{tabular}

\section{Table 1 Per Capita Solid Waste Generation in Cubic Meter $\left(\mathbf{M}^{3}\right)$}

Source: Field Survey June 2017

The volume of solid wastes general in Bauchi metropolis is relatively small but absence of segregation practice at the household level and ineffective evacuation were possibly the major factor

Responsible for the continues accumulation of solid wastes on the metropolis

\section{Quantity of Solid Waste Generated In Bauchi Metropolitan Area}

Still quantitatively, this research discovered that the amount of solid waste generated in Bauchi metropolis is $0.16 \mathrm{~kg}$ lower than the national average per capita which is $1.02 \mathrm{~kg} / \mathrm{capita} / \mathrm{day}$. The average solid waste generated in high density residential areas at $0.79 \mathrm{~kg} /$ capita/day; $0.89 \mathrm{~kg} / \mathrm{capita} /$ day for medium density residential areas and $1.03 \mathrm{~kg} / \mathrm{capita} /$ day low-density residential areas. The general average per capital solid waste generated was $0.86 \mathrm{~kg} / \mathrm{capita} /$ day. See table 2 below.

Table 2 Per Capita Solid Waste Generation In kilogramme (Kg)

\begin{tabular}{|c|c|c|c|c|c|c|c|c|}
\hline Ward & Density & Garbage & Rubbish & Trash & Ash & Polythene & $\begin{array}{c}\text { Total } \\
\text { (kg) }\end{array}$ & Average (kg) \\
\hline Old G R A & Low & 1.12 & 0.99 & 1.00 & 0.45 & 1.57 & 5.13 & 1.03 \\
\hline New G R A & Low & 1.28 & 0.90 & 1.10 & 0.30 & 1.44 & 5.02 & 1.00 \\
\hline F/Mada & Low & 1.02 & 1.11 & 0.80 & 0.65 & 1.31 & 4.89 & 0.98 \\
\hline Yelwa & Medium & 0.86 & 0.91 & 1.03 & 0.77 & 0.99 & 4.56 & 0.91 \\
\hline Dan Iya & Medium & 0.76 & 0.83 & 0.91 & 0.64 & 0.87 & 4.01 & 0.80 \\
\hline Makama & Medium & 0.62 & 0.58 & 0.75 & 1.08 & 1.00 & 4.03 & 0.81 \\
\hline I/ Bako & Medium & 0.80 & 0.92 & 0.78 & 0.87 & 1.04 & 4.41 & 0.88 \\
\hline Nassarawa & High & 0.37 & 0.75 & 0.50 & 1.34 & 0.54 & 3.50 & 0.70 \\
\hline Dan Kade & High & 0.52 & 0.67 & 0.71 & 1.54 & 0.80 & 4.24 & 0.85 \\
\hline Dawaki & High & 0.41 & 0.82 & 0.49 & 1.66 & 0.61 & 3.99 & 0.80 \\
\hline Dan Amar & High & 0.52 & 0.54 & 0.62 & 1.47 & 0.48 & 3.49 & 0.70 \\
\hline Hardo & High & 0.61 & 0.47 & 0.51 & 1.21 & 0.69 & 3.49 & 0.70 \\
\hline Total (kg) & & 8.75 & 9.49 & 9.20 & 12.0 & 11.31 & $\mathbf{5 0 . 7 4}$ & \\
\hline Average (kg) & & 0.73 & 0.79 & 0.77 & 1.00 & 0.95 & & \\
\hline
\end{tabular}




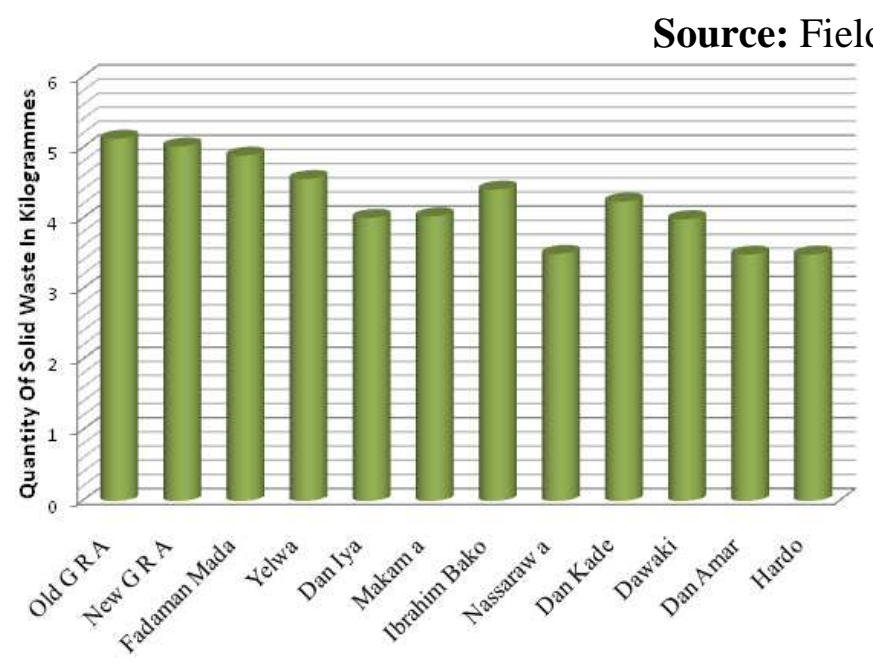

Wards in Bauchi Metropolis

Source: Field Survey, June 20117

\section{Figure 4.1 Quantity of Solid Waste Generation By Wards.}

From the figure above, it can be deduced that income and quantity of solid waste generation are directly and proportionately related as high income areas like GRAs generally generate more waste

\section{Characteristics of Solid Waste Generated}

Researchers have revealed that income level of a society determines the type of its solid waste. In general the higher a country's level of industrialization the higher its income level and the larger its proportion of toxic, non-organic and no biodegradable.
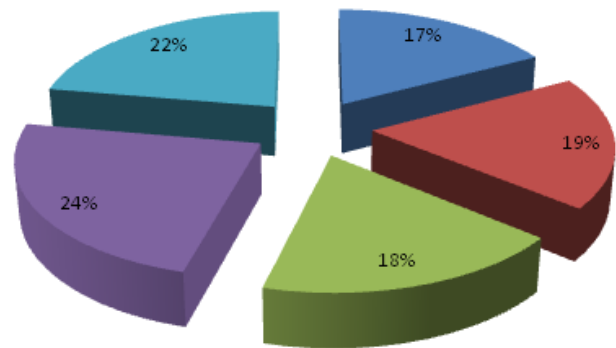

Fig Types of Solid Waste Generated in Bauchi Metropolis

Figure 4.3 Characteristics of solid waste Generated in Bauchi Metropolis

High-income earners consume more of processed and packaged than raw products, which result in a higher percentage of inorganic materials - metals, plastics, glass, and textile. Waste characteristics vary according to season, income level, population, social behaviour, climate, and industrial production, the size of markets for waste materials and the extent of urbanization, effectiveness of recycling, and work reduction. The higher the level of economic development, the higher the quantity of inorganic materials in the waste stream Table 2 shows a comparative analysis of municipal solid waste composition in some major cities in Nigeria. It can be seen that great majority of the total solid waste generated in Nigeria is organic.

\section{Relationship between Education, Income and Solid Waste Generation}

In the research it is revealed that a direct and proportional relationship exist between education, income and the quantity of solid waste generation. It is found that as educational level increases, the income level also rises and those with high income generate more solid waste than those with low income as shown in figure 3 below

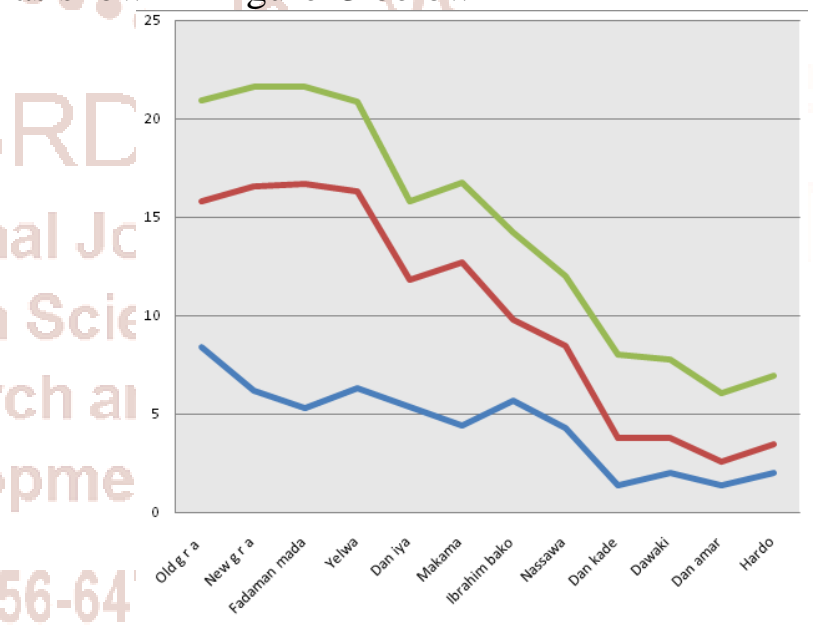

Source: Field Survey, June 2017

Figure 3Relationship between Education, Income and Waste Generation

\section{Conclusion}

It is certain, that Solid waste composition and characterization analysis are critical in management of municipal solid waste. Segregation, based on physical characteristics, of household solid waste at source is a panacea for effective management of solid waste. The exercise should be carried out in three stages as follows: The first stage should be the separation of toxic waste from non-toxic waste. The toxic waste like batteries, chemicals, paints and others should be carefully be separated from other wastes and stored in a covered storage facility and kept out of reach of children. At the second stage, the non-toxic waste which contains recyclable and non-recyclable materials should also 
be sorted into two groups. The non-recyclable materials which comprises of ash, garbage, food scrubs and other biodegradable materials should be taken to communal collection centres for onward evacuation to disposal site. The final stage should be the separation of the recyclable materials into metallic and aluminium's materials in one container and polythene and plastics on the other container.

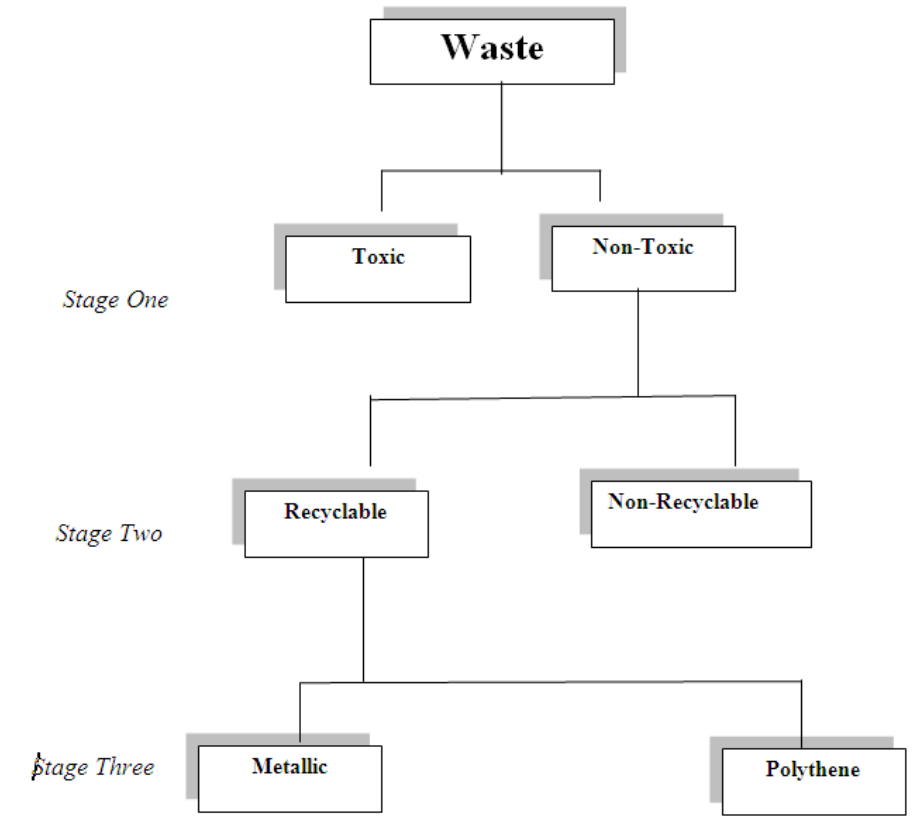

Figure 4 Stages of Solid Waste Segregation at the Household Level

Three temporary storage containers of different sizes and colours that can contain all the solid waste that can be generated in a week, at household level; one with cover for toxic waste, one for metals and aluminium's and the other for plastics and polythene should be kept at the household level.

Efforts should be made by stakeholders to evolve policies for disposal, waste reduction and recycling project. There is need for adequate budgetary provision for Abuja Environmental Protection Board, AEPB for proper training and replacement of the existing vehicles with modern equipment to reduce operating costs. The agency should also encourage community participation and involvement in waste management. Also formal composting and recycling facilities should be setup at Gosa dumpsite

\section{References}

1. Babcock and Wilcox Volund (2003), Computational Fluid Dynamics in Waste-toEnergy Technology. Pamphlet
2. Glusszynski Powel (1995), Types of incinerators based on Technological Features. Waste Prevention Association, Greenpeace.

3. Kamel, L. I., (1994). Mokattam Garbage Village, Cairo, Egypt, Stallion Graphics, Cairo, Egypt.

4. Keziah K. L. (2009), A Study Of Residential Solid Waste Management In Bauchi Traditional Area. Unpublished Project, Abubakar Tafawa Balewa University, Bauchi

5. Kinnaman, T. C. And D. Fullerton. (2000). the Economics of Residential Solid Waste Management. In Tietenberg, T. and H. Folmer, 2000, The International Yearbook Of Environmental And Resource Economics 2000/2001: A Survey of Current Issues. Edward Elgar.

6. Kneese, A. V.; R. U. Ayres and R. C. D'Arge. (1970). Economics and the Environment: A Materials Balance Approach. Resources for the Future, Washington, D.C,

7. Mantell C. A. (1975). Solid Waste Origin Collection Processing and Disposal. John Willey and Sons Inc. London,

8. Miller G. T.(1990), Living In The Environment: An Introduction To Environmental Science. Wadsworth Publishing Company, Belmont, California

9. Musa H. K (2004). Characterization of Kano urban waste for composting production, Unpublished M. Eng Thesis, Civil Engineering department, Bayero University, Kano,

10. Oluwande P. (1991). Assessment Of Metropolitan Waste Management Problem In China And Africa, In Managing

11. Solid Waste in Developing Countries Ed. J.D. Holmes. John Willey and Sons New York.

12. Rajesh, B.K., S. Suresh A.K. Sharma, (2013)"characteristics of Municipal solid waste Generated by the city of Bhopal, India," International Journal of ChemTechh Research CODEN USA: IJCRGG, VOL.5, No.2 pp 623628, April - June, 2013.

13. Yongziang YANG ET AL (2003), Modelling of the fuel stream and Combustion in a Rotary-Kiln Hazardous Waste Incinerator, $3^{\text {rd }}$ International Conference on

14. CFD in the minerals and process Industries CSIRO, Melboune, Australia, December 10-12. 